\title{
Mentored, Unpaid Design Team Internship Experience
}

\section{Prof. Peter J. Schubert, Indiana University Purdue University, Indianapolis}

Schubert is a Professor of Electrical and Computer Engineering and serves as the Director of the Richard G. Lugar Center for Renewable Energy (www.lugarenergycenter.org) and is the faculty advisor for Students for the Exploration and Development of Space (SEDS) at IUPUI. He holds 40 US Patents, a Professional Engineering License (Illinois), and has published over 95 technical papers and book chapters. Schubert has managed research projects from USDA, NASA, DOE, NSF, and DoD. 


\title{
Mentored, Unpaid Design Team Internship Experience
}

\begin{abstract}
An international team of 7 undergraduate interns working pro bono during the summer made significant advances in several areas of Space Solar Power. Distinct from a capstone design effort, this study group revived the practice common in the 1970s and 1980s of considering broad topics of high relevance to public citizens and elected decision-makers. Significant obstacles to success included lack of research experience, lack of motivating paycheck, and a highly-complex system under study. Each student was assigned a mentor from the aerospace industry or academia to guide the creation of a research plan, and to periodically review progress. Team-building exercises were conducted to develop relationships, and weekly team workshops were held to teach interoperability with other subsystems. Student experiences shifted from excitement at the outset to a sense of being overwhelmed with the magnitude and difficulties associated with a space-based project running in the tens of billions of dollars. Yet, each student was able to overcome such mid-term concerns, and to make a meaningful contribution to a key research question. Their results were published at a national space conference with all students listed as co-authors. The present work assesses the formation of such an unpaid team and the management thereof, analyzes the techniques used to encourage desired outcomes, and finishes with post-project follow-up on perceptions and career choices. This approach may find interest among professors with limited funds who seek to develop solid preliminary data to make grant applications more competitive.
\end{abstract}

\section{Introduction}

Aerospace research can be expensive and may require specialized facilities. Faculty just getting started in settings without extensive hardware may need to bootstrap their research activities by developing preliminary research. Presented herein is a team project, based on aerospace study groups on space solar power and space colonization in the 1970s and 1980s, to address complex space systems. The team of undergraduate students worked pro bono during the summer break from college. Results were published in a paper at a major space conference which featured 7 students as contributing co-authors.

Many college-age young people become excited at potential solutions to worrisome issues and trends such as renewable energy, climate change, nuclear proliferation, and peak oil [1-3]. When Space Solar Power (SSP) is explained [4-9] there is considerable interest; however, the pathway to making such concept realized in practice can be perceived as long, difficult, and mysterious [10]. The dual purpose of the summer 2015 SSP Wireless Power Transfer (WPT) research team was to help create aerospace researchers and to flesh out advanced concepts proposed by the faculty supervisor (see Figure 1) [11]. 


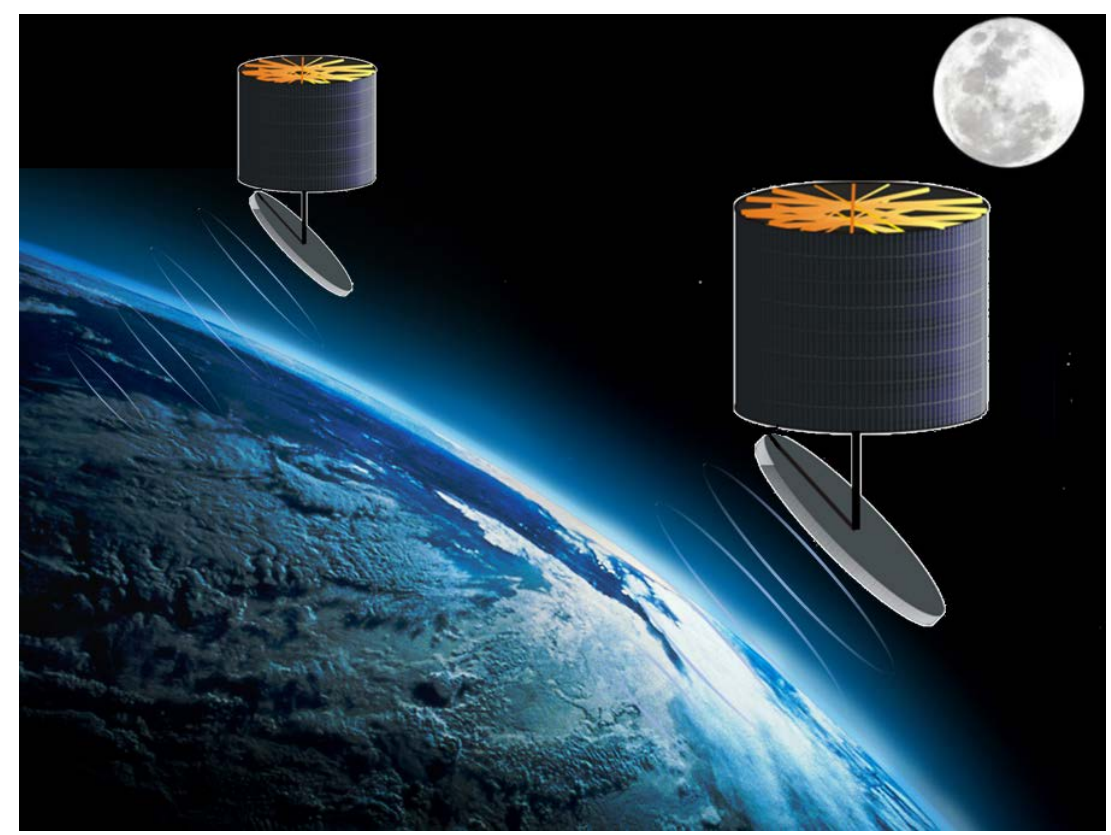

Figure 1. Solar Power Satellites (SPS) collecting sunlight in orbit and delivering Wireless Power Transfer (WPT) to terrestrial receiving antennae. This system is called Space Solar Power (SSP).

Complex systems require multi-disciplinary teams working cooperatively to integrate their findings into a comprehensive whole. Engineering capstone projects are a good model however, they tend to include students within a single department and may lack the academic diversity needed in a holistic study. Ultra-ambitious efforts like SSP are likely to require international participation, so an objective of the SSP-WPT team was to include representatives from several nations as well.

Attracting students to a summer internship generally requires pay. To offer college credits generally requires tuition. Asking students to work pro bono is asking a lot, and generally requires that the student have some other means of support. Finding such students is not simple. Retaining such students is a challenge, especially as some may have started a summer without a job, but may eventually obtain employment which reduces or eliminates the time they can devote. Added to this, the often-encountered aura surrounding the word "research" may cause anxiety among students who lack peers or role models. Undergraduate students may consider research something “only graduate students do" [12].

Described herein is the origin, genesis, recruiting, management, and execution of a pro bono undergraduate research team study, the supervision and motivation of the students, and a field trip and "team-building experience” (paintball games). Industry mentors were solicited to edit Research Plans, review intermediate results, and to attend a final group webinar. The results generated by the students were included in a technical paper which they can cite on their resumes [13]. A follow-up study conducted 6 months after the event shows the results of reflection.

\section{Team Formation}

University faculty administrators and lab center directors often receive many more unsolicited emails from students seeking research assistantships or summer intern positions than do other 
faculty members. One practice for faculty just getting started in engineering research is to request forwards from research directors to expand their pool of candidates. Certain international institutions place such a high value on overseas intern experience, and have such large pools of students seeking postings, that it is possible to request that only students needing no recompense be considered. This is somewhat unconventional, and engagement with administration is recommended. In negotiation with prospective interns it is expected that there be some means to defray expenses from the hosting faculty or academic unit. This can take the form of finding housing, as students from many foreign cultures may be quite comfortable sharing an apartment where alternative sleeping arrangements can be made (e.g. a sofa or inflatable mattress). Social media contacts can be especially useful in making such connections, and help serve to bring visiting students into a pre-established local community. Hosting faculty should offer the courtesy of transport from the airport to their lodging - a friendly face upon arrival is very important. Another helpful compensation is pizza at team meetings, plus local field trips, and social dinners at the faculty member's home [14].

Following two summers hosting small research teams from selected institutions, in the lead-up to Summer 2015 a bold new approach was attempted and found to be successful. Every student query received a reply asking if the student would be willing to work at no charge ("pro bono"). Certainly this quickly ended communications with most inquirers. However, a percentage responded favorably, in this instance, being about $10-15 \%$. Certain nations and universities offer programs to their undergraduate students which encourage overseas study and internships, in some cases even providing a stipend to the students. These are excellent opportunities for faculty members to work with talented students with the potential to enroll in graduate programs and conduct further research. In fact, a motivating factor for some students is the potential to contribute to preliminary results which allow the faculty member to secure funding which includes a research assistantship to continue the same work. Thus, a pro bono internship could be viewed as an investment in future academic endeavors.

Initially 10 students indicated acceptance of a pro bono research project based on a brief explanation of the topic: a new design for a solar power satellite, and a multi-disciplinary study of the wireless transfer of power to the earth. One student never arrived, and another left midway through the project due to family reasons. Among the participants 3 countries outside of the US were represented and the team included 2 females (see Figure 2). 


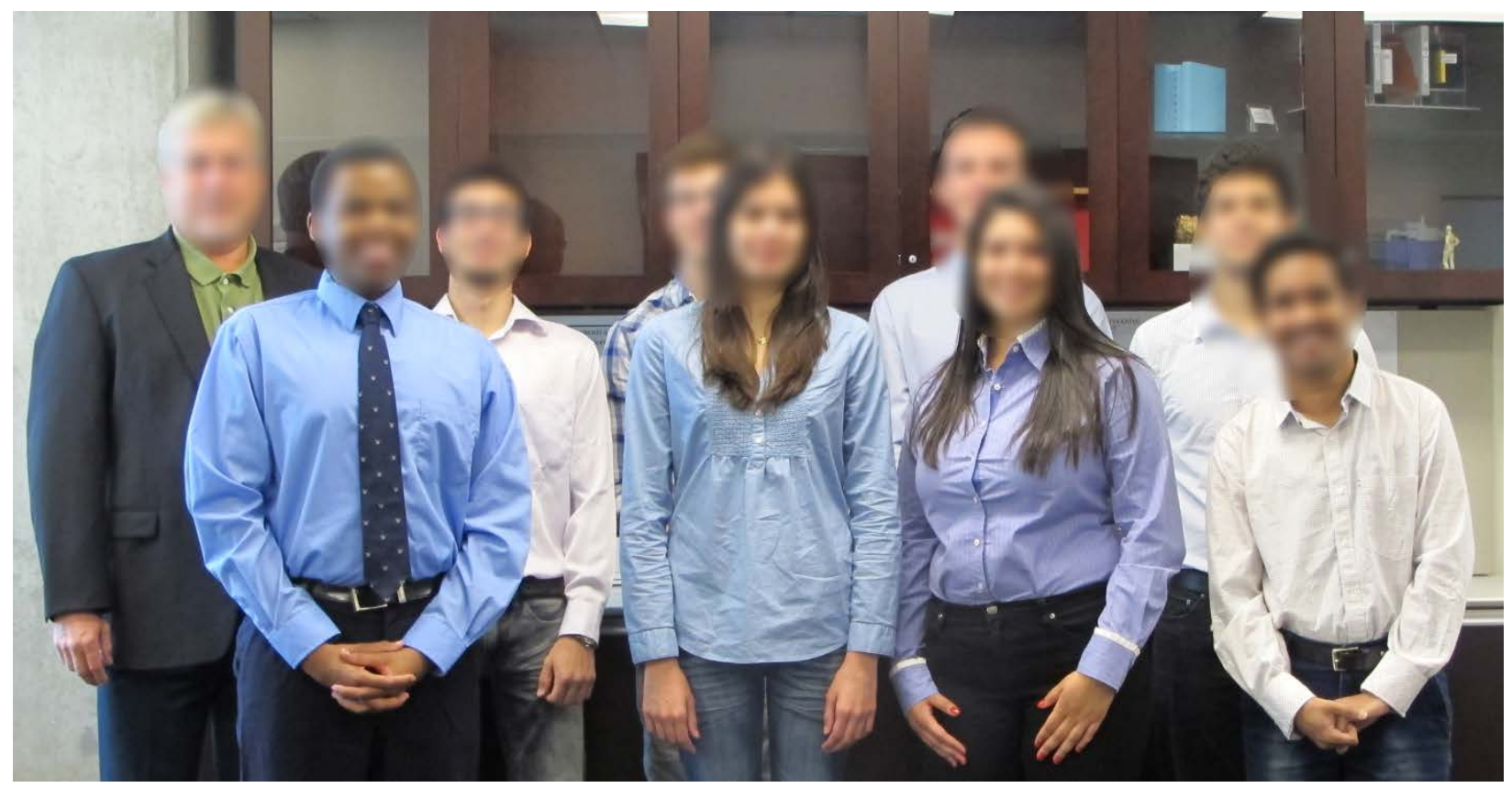

Figure 2. Summer 2015 SSP-WPT Research Team

\section{Mentors}

The study of SSP is dispersed geographically with only a few centers focusing on this potentially world-changing technology. There is little or no federal funding available from US agencies such as DOE, DoD, or NASA. A small, but increasing, number of conferences and workshops are held, and larger space conferences often include a technical track on SSP. Often, individual researchers contribute to this field using discretionary time from their employers. Within such an environment collaboration between SSP architects and technologists can be tenuous and lower in priority than other responsibilities. As a means to provide increased interaction, and of course, to bring benefits to the students, a number of industrial, academic, and not-for-profit subject matter experts were solicited to provide mentoring to the summer interns.

Acceptance rate by mentors was very high. During the request for their service it was stressed that their overall effort was expected to be just 4 hours spread across 10 weeks, including: editing and comments on a 2-4 page Research Plan to be completed by each student at the conclusion of week 2; (2) a 1-hour conference call with the student and supervising faculty to review intermediate progress and expected deliverables; and (3) participation in a 2-hour webinar where each student summarizes their results. A common and welcome outcome of the intermediate conference call was greater awareness between the mentor and faculty supervisor of each other's research thrust. With so many space conferences to choose from, it is often a challenge to establish long-term relationships with peers from other parts of the country. The mentoring aspect of this project thus had auxiliary benefits. Results of the survey (Figure 3) affirm the benefits accrued to the students. 


\begin{tabular}{l|c}
\hline Answer Choices & Responses \\
\hline$>\quad$ I learned a lot from my Mentor & $80 \%$ \\
\hline$\quad$ Having a Mentor is an experience I would want to have again & $400 \%$ \\
\hline$\quad$ My Mentor helped me to understand the technical field and industry & 5 \\
\hline$\quad$ I was exposed to topics I never knew about through contact with my Mentor & $100 \%$ \\
\hline Total Respondents: 5 & 5 \\
\hline
\end{tabular}

Figure 3. Survey responses regarding project mentors.

\section{Overcoming Feelings of Being Overwhelmed}

Students arrived generally excited at the topic. Based on their interests and backgrounds, each student was assigned as the primary contributor to a list of sub-topics, and most were assigned as a secondary contributor to a different topic. The first part of the summer involved weekly team meetings, individual consultations with the faculty supervisor, and reading from the background materials made available on a shared file server. The volume of background information was somewhat daunting, making it a challenge to know what to read first. As the students began making their own contributions, according to the sub-topic list, there arose among many of them a feeling of being overwhelmed. An anecdote serves to capture this common emotion.

The sheer magnitude in scale of the project assigned to one student was overwhelming at first. After meeting with his industry mentor and speaking of megawatts, he returned to his own work on the gigawatt scale, with literally tens of millions of interacting components required, millions of volts, materials massing thousands of tons, and hardware costing tens of millions of dollars. Perhaps nothing in his life had prepared him for this. Visualization at such scales is difficult; and developing an intuitive sense of whether the calculations are correct does not come easily. In one meeting, as he presented his latest results in an incredulous voice, not sure if the numbers were really so huge, I offered him a story, referencing the film The Matrix, and the overarching goal of our work to save the planet with clean energy. "Remember what the Oracle said to Nemo," I began, then spoke to him directly: "You're not The One, kid. Sorry." He quipped, respectfully and with a lop-sided grin: "But he was The One." Everybody on the team chuckled. It was a turning point for this student, and his progress accelerated after that and concluded with rock-solid engineering work.

Almost every student had some level of anxiety which is reflected in the results of a survey conducted 6 months after the conclusion of their internship. It is clear that the students did not fully appreciate that magnitude of expectations at the start. After reflection of a bit more than 1 semester there appears to be a dichotomy between those who feel empowered and those who did not gain that level of confidence from their research experience (see Table 1). At least 1 student was very shy and possibly intimidated by the faculty supervisor which did not allow for full participation. The team building experience was especially helpful at overcoming these feelings. 


\begin{tabular}{|c|c|c|c|c|c|}
\hline $\begin{array}{c}\text { SURVEY RESULTS } \\
\text { ON FEELING } \\
\text { OVERWHELMED }\end{array}$ & Not at all & $\begin{array}{c}\text { Maybe a little } \\
\text { bit }\end{array}$ & $\begin{array}{l}\text { Yes, I did get } \\
\text { freaked out at } \\
\text { one point }\end{array}$ & $\begin{array}{l}\text { Definitely I } \\
\text { had a feeling } \\
\text { of being } \\
\text { overwhelmed } \\
\text { for a while }\end{array}$ & $\begin{array}{c}\text { I still feel like } \\
\text { it was too } \\
\text { difficult for } \\
\text { me }\end{array}$ \\
\hline- & $0 \%$ & $20 \%$ & $20 \%$ & $60 \%$ & $0 \%$ \\
\hline $\begin{array}{l}\text { Did you realize from } \\
\text { the first week that } \\
\text { this would be a huge } \\
\text { challenge? }\end{array}$ & 0 & 1 & 1 & 3 & 0 \\
\hline- & $0 \%$ & $0 \%$ & $60 \%$ & $40 \%$ & $0 \%$ \\
\hline $\begin{array}{l}\text { At the midpoint of } \\
\text { the summer, did you } \\
\text { eventually realize } \\
\text { how difficult your } \\
\text { assignment really } \\
\text { was? }\end{array}$ & 0 & 0 & 3 & 2 & 0 \\
\hline- & $20 \%$ & $40 \%$ & $20 \%$ & $0 \%$ & $20 \%$ \\
\hline $\begin{array}{l}\text { Now, } 6 \text { months later, } \\
\text { how do you feel } \\
\text { about the level of } \\
\text { difficulty? }\end{array}$ & 1 & 2 & 1 & 0 & 1 \\
\hline
\end{tabular}

Table 1. Survey results on Feeling Overwhelmed

\section{Field Trip and Team-Building}

Local to the university is a very large rooftop solar photovoltaic installation (circa $2 \mathrm{MW}$ ) which includes a test patch for alternate PV configurations. We were able to have the primary manager provide a guided tour. Of particular interest to the study of a solar power satellite was the power distribution and management. The team was able to see the combiner boxes, switchgear housing, and large bus bars which will also be needed on an orbiting solar farm. Lunch after the tour was the first meal the team shared aside from the "working lunches" held each week where the professor ordered vegetarian pizza. The conversation relaxed as the meal progressed, and many of the students expressed curiosity and interest in the backgrounds and cultures of their team members - something which was not occurring in the more formal setting of a research center conference room (Fig. 1). Several amazing stories ensued, which gave other students a topic upon which to initiate conversations of a non-technical nature.

To cement the team-building portion of the field trip, the team had selected a paintball game over several alternatives. The weather was wet and everyone became dirty. One group determined to focus on the professor (who was winning every game), and another to defend him. When other players joined the games, these teams grew, chose their own names, and participated in friendly "trash talk" banter within this competitive environment of playing "capture the flag”. The ride 
back to campus was of a completely different nature than the out-going trip. Students were much more relaxed, more vociferous, and joyful despite the grime and soggy clothing. This exercise became a starting point for conversations back in the formal meeting room, and helped establish feelings of camaraderie, bonhomie, esprit de corps, and aligned purpose. Although hard to measure quantitatively, the quality of work seemed to improve. Student perceptions are shown in the following chart.

\begin{tabular}{|l|c|c|c|c|c|c|}
\hline $\begin{array}{l}\text { SURVEY RESULTS ON } \\
\text { TEAM-BUILDING }\end{array}$ & $\begin{array}{c}\text { Do not } \\
\text { agree }\end{array}$ & $\begin{array}{c}\text { Agree } \\
\text { slightly }\end{array}$ & $\begin{array}{c}\text { Neutral - } \\
\text { no strong } \\
\text { opinion }\end{array}$ & Agree & $\begin{array}{c}\text { Strongly } \\
\text { Agree }\end{array}$ & $\begin{array}{c}\text { Weighted } \\
\text { Average }\end{array}$ \\
\hline- & $0 \%$ & $0 \%$ & $0 \%$ & $60 \%$ & $40 \%$ & \\
\hline $\begin{array}{l}\text { This experience } \\
\text { helped me to work } \\
\text { more effectively } \\
\text { with other Interns }\end{array}$ & 0 & 0 & 0 & $\mathbf{3}$ & $\mathbf{2}$ & $\mathbf{4 . 4}$ \\
\hline- \\
\hline $\begin{array}{l}\text { I was able to relate } \\
\text { to my Professor on a } \\
\text { more personal level }\end{array}$ & 0 & 0 & $\mathbf{1}$ & $\mathbf{2}$ & $\mathbf{2}$ & $\mathbf{4 . 2}$ \\
\hline-
\end{tabular}

Table 2. Survey results on team-building and field trip.

\section{Lessons Learned}

Each research topic addressed either: (a) a unique aspect of the recently-published "tin-can" solar power satellite; or (b) an issue expected to be of concern to the general public. The topics were:

1. Wireless Power Transfer with low side-lobe intensity - needed to avoid desense of terrestrial communications equipment and spectra.

2. Atmospheric Attenuation and Heating - important for comparisons to fossil fuel plants vis-à-vis global warming.

3. Rectenna Design and Emplacement - studying land-use changes, environmental impacts, and costs for receiving antenna arrays in temperate latitudes.

4. Structural Design of SPSs - structural framework and guy wires for a very large, rotating cylindrical shell held in tension to preserve shape.

5. Power Management and Distribution - to our knowledge the first study of how tens of millions of individual solar panels are combined, converted, and distributed in the spacetenna array elements. 
6. SPS Assembly - study of robots, fasteners, and methods for highly-automated construction and repair.

7. Frequency and Orbital Slot Allocations - review of frequency spectrum challenges and GEO positional allocations anticipating conflicts with existing allocations.

8. Grid Interface and Loading - to our knowledge the first-ever detail on combining DC power across the rectenna and interfacing with the transmission grid.

9. Budget.

Contributions from each of these areas were included in a paper published in September 2015 [13], proximate in time to the conclusion of student work and thereby providing rapid feedback and reward. The prospect of this publication was an important motivating factor.

Students working pro bono have less incentive to remain on the team than those who are working for pay or for college credit. Several students on the team held part-time jobs. In general they were expected to devote 20 hours per week to their projects. Weekly progress meetings linked to the Research Plans helped maintain focus, but another method was also used. The student assigned to the Budget was tasked with ensuring that others supplied, at first, framework to the budget, and, later, specific costs. Thus, both the Research Plan and the Budget served as vehicles for helping to assure steady progress and project completion.

Starting with more students than the project required was appropriate. In particular, this made it easy to gracefully accede to a student request to depart from the team for whatever reason. A concern raised within the academic unit was that the processing of students having access to computers and the library should be compensated. For those students sponsored by their country or their university, this was accomplished by setting up an independent study 1 credit course requiring a final report as the only deliverable. Students without this opportunity were made "academic no-pay" and received no college credit. In the future, some level of payment will be expected, significantly reducing objections from hard-working academic staff members.

The student-mentor relationship served a very useful role by bringing in an independent professional to which the student felt an obligation in performance and communication. In all cases, the mentor's qualifications were impressive to the students. In most cases the mentors never met their mentees in person but those that did meet were grateful. Shy students, or those with lower self-esteem should receive prioritization for in-person meeting with local mentors.

The model of assigning students projects beyond what might be considered appropriate for their level of academic attainment encourages them to realize more of their own potential. However, this was not universally appreciated. A more careful tailoring of tasks to student background experience and motivation level would be advised. A summary of student perceptions at the start, in the middle, and 6 months after the project are shown in Table 3, which was collected in January 2016. The most exciting outcome is that so many of the students express eagerness to participate in research again. 


\begin{tabular}{|c|c|c|c|c|c|}
\hline $\begin{array}{c}\text { SURVEY } \\
\text { RESULTS ON } \\
\text { SCIENTIFIC } \\
\text { RESEARCH }\end{array}$ & Not at all & $\begin{array}{c}\text { Maybe a little } \\
\text { bit }\end{array}$ & $\begin{array}{l}\text { Yes, I did get } \\
\text { freaked out at } \\
\text { one point }\end{array}$ & $\begin{array}{l}\text { Definitely - I } \\
\text { had a feeling } \\
\text { of being } \\
\text { overwhelmed } \\
\text { for a while }\end{array}$ & $\begin{array}{l}\text { I still feel like } \\
\text { it was too } \\
\text { difficult for } \\
\text { me }\end{array}$ \\
\hline- & $0 \%$ & $20 \%$ & $20 \%$ & $60 \%$ & $0 \%$ \\
\hline $\begin{array}{l}\text { Did you realize } \\
\text { from the first } \\
\text { week that this } \\
\text { would be a huge } \\
\text { challenge? }\end{array}$ & 0 & 1 & 1 & 3 & 0 \\
\hline- & $0 \%$ & $0 \%$ & $60 \%$ & $40 \%$ & $0 \%$ \\
\hline $\begin{array}{l}\text { At the mid-point } \\
\text { of the summer, } \\
\text { did you } \\
\text { eventually } \\
\text { realize how } \\
\text { difficult your } \\
\text { assignment really } \\
\text { was? }\end{array}$ & 0 & 0 & 3 & 2 & 0 \\
\hline- & $20 \%$ & $40 \%$ & $20 \%$ & $0 \%$ & $20 \%$ \\
\hline $\begin{array}{l}\text { Now, } 6 \text { months } \\
\text { later, how do you } \\
\text { feel about the } \\
\text { level of } \\
\text { difficulty? }\end{array}$ & 1 & 2 & 1 & 0 & 1 \\
\hline
\end{tabular}

Table 3. Survey results on attitudes or appreciation for scientific research.

\section{Acknowledgements}

The author wishes to acknowledge the brave young men and women who participated and completed their roles in the SSP WPT Internship team of Summer 2015. Individual names will be added to the final paper. It is the hope of the author to secure funding from which these students can draw research assistantships and continue their work in advancing aerospace engineering in a social context. Longitudinal study of post-graduation career paths will also be studied.

VIII. Bibliography

${ }^{1}$ US Global Change Research Program, Climate Change Science Program, “Climate Literacy: The Essential Principles of Climate Science,” March 2009.

${ }^{2}$ National Research Council, Hidden Costs of Energy Production, The National Academies Press, 2009 
${ }^{3}$ Leidy Klotz, Geoff Potvin, Allison Godwin, Jennifer Cribbs, Zahra Hazari and Nicole Barclay, "Sustainability as a Route to Broadening Participation in Engineering,” DOI: 10.1002/jee.20034, J. Engr. Ed. v.103, no 1, pages 137153, January 2014.

${ }^{4}$ Glaser, P. E.; "Power from the Sun; Its Future", Science, No.162, pp.857 - 886, 1968

${ }^{5}$ Potter, S.D., et. al., "Space Solar Power Satellite Alternatives and Architectures,” AIAA Aerospace Sciences Mtg., Orlando, FL, 5-8 Jan 2009.

${ }^{6}$ Mankins, J.C., “Space Solar Power: New Architectures, Concepts and Technologies,” IAF-97-R.2.03, 38 ${ }^{\text {th }} 1997$.

${ }^{7}$ Rouge, J.D., "Space-Based Solar Power As an Opportunity for Strategic Security: Phase 0 Architecture Feasibility Study,”, Natl. Security Space Office, 9 Oct 2007.

${ }^{8}$ Dept. of Energy, “Satellite Power System: Concept Development and Evaluation Program,” DOE/ER-0023, 1978.

${ }^{9}$ Schubert, P.J., “Costs, Organization, and Roadmap for Space Solar Power,” Online J. of Space Comm., v. 16, 5 pgs.

${ }^{10}$ Fuller, R.B., Critical Path, St. Martin’s Press, 1981.

${ }^{11}$ Schubert, P., “Energy Resources Beyond Earth - SSP from ISRU,” Gateway-to-Space 2014, St. Louis, MO, Nov 7-9, 2014.

${ }^{12}$ Lima, R. M.,D. Carvalho, R. M. Sousa,A.Alves, F. Moreira, D. Mesquita, and S. Fernandes. 2012. “AProject Management Framework for Planning and Executing Interdisciplinary Learning Projects in Engineering Education.” In Project Approaches to Learning in Engineering Education: The Practice of Teamwork, edited by L. C. d. Campos, E. A. T. Dirani, A. L. Manrique, and N. van Hattum-Janssen, 53-76. Rotterdam: Sense Publishers.

${ }^{13}$ Schubert, P.J., Pinto, S.M., Pires, B.C., do Nascimento, M., Barks, E., Nderitu, J., Goncalves, G., Tokmo, F., “Analysis of a Novel SPS Configuration Enabled by Lunar ISRU,” Proceedings AIAA SPACE 2015, Pasadena, CA, 31 Aug. - 2 Sept. 2015.

${ }^{14}$ David Goodman, Patricia Fox, Jan Cowan, Joe Tabas, "How to Establish Successful International Experiences for Engineering and Technology Students,” Technology Interface International Journal, v. 14, 2014. 